\title{
A Study to Assess Contributing Factors of Teenage Pregnancy in Sunsari District of Nepal
}

\author{
Laxmi Gautam', Anup Gupta ${ }^{2}$, Rabina Khadka', Gobind Prasad Pant ${ }^{4}$ \\ ${ }^{1,2,3,4}$ Department of Public Health, Manmohan Memorial Institute of Health Sciences, Tribhuvan University, Kathmandu, Nepal. \\ DOI: https://doi.org/10.24321/2349.2880.202007
}

I $\quad \begin{array}{llll}\mathbf{N} & \mathbf{F} & \mathbf{O}\end{array}$

Corresponding Author:

Laxmi Gautam, Department of Public Health, Manmohan Memorial Institute of Health Sciences, Tribhuvan University, Kathmandu, Nepal.

E-mail Id:

laxmi.dp26@gmail.com

Orcid Id:

https://orcid.org/0000-0003-3926-8912

How to cite this article:

Gautam L, Gupta A, Khadka R, Pant GP. A Study to Assess Contributing Factors of Teenage Pregnancy in Sunsari District of Nepal. Ind J Youth Adol Health 2020; 7(2): 5-11.

Date of Submission: 2020-08-23

Date of Acceptance: 2020-10-15

\section{$\begin{array}{llllllll}\mathbf{A} & \mathbf{B} & \mathbf{S} & \mathbf{T} & \mathbf{R} & \mathbf{A} & \mathbf{C} & \mathbf{T}\end{array}$}

Background: Early child bearing is a widely observed phenomenon in Nepal. However, little information is available in regard to its contributing factors. Teenage pregnancy is major contributing factor of maternal and child health and a challenging issue of public in developed and developing countries. This study explores the contributing factors of teenage pregnancy and knowledge about its consequences.

Methodology: A descriptive study was conducted to find out contributing factors of teenage pregnancy among 102 pregnant teenagers at selected health facilities of Sunsari district. Pregnant teenagers visiting health facilities for antenatal check-up during study period were interviewed using pre-designed questionnaire. Data was managed using SPSS software. Descriptive statistics and chi square test were used.

Result: The mean age of teenage pregnancy was $18 \pm 1.04$ years and age at marriage $16.69 \pm 1.09$ years. Majority were Muslim, $86.3 \%$ were homemaker, $31.4 \%$ had positive history of teenage pregnancy in family either-side, $38.2 \%$ had married at an age of 17 years, $31.4 \%$ were pregnant with their first child. Inadequate knowledge about teenage pregnancy, cultural acceptance, illiteracy, lack of knowledge on consequence of teenage pregnancy, difficulty to get information and access on family planning methods were major contributing factors and school dropout was reported as consequences of teenage pregnancy. Ethnicity, religion and education were associated with knowledge of teenage pregnancy.

Conclusion: Knowledge about the risk and drawbacks of early marriage and early pregnancy should be increased not only among teenage girls but also to their parents and in-laws to change the attitude and practice of early marriage and teenage pregnancy.

Keywords: Contributing Factor, Teenage Pregnancy, Early Marriage

\section{Introduction}

Teenage pregnancy is the pregnancy which occurs before the age of 20 years is a major public health concern of both developed and developing countries. ${ }^{1}$ Globally, teenage pregnancy is second leading cause of mortality in 15-19 years old age group. An estimated 16 million girls aged between 15-19 years old gives birth every year with over $90 \%$ of teenage pregnancy estimated to occur in low and 
middle income countries, making up to $11 \%$ of all birth globally. ${ }^{2}$ The risk of death due to pregnancy-related causes is double among women aged 15-19 compared to women in their twenties. ${ }^{3}$

South Asia is ranked second to Sub-Saharan Africa with the highest rate of adolescent pregnancy. Practice of early marriage, poverty, and social expectation to have early child are considered key drivers of adolescent pregnancy in south Asia. ${ }^{4}$ Within South Asia, the recorded teenage pregnancy rate is highest in Bangladesh 35\% followed by Nepal 21\% and India 21\%. ${ }^{5}$

According to Nepal Demographic Health Survey (NDHS) 2016 report of Nepal, $17 \%$ of women age 15-19 have begun childbearing; $13 \%$ have had a live birth, and $4 \%$ were pregnant with their first child. Average age at first pregnancy was lowest in Province 2 which was 19.2 years. ${ }^{6}$ Teenage pregnancy can have significant effect on the level of education of women, their employment opportunities and marital stability and it increases their economic and social dependency on family. ${ }^{7}$ The factors influencing the increase of teenage pregnancy are not well known, however hypothetically inadequate knowledge about reproductive health, inaccessibility to reproductive health services, poverty, early sexual practice, negative culture and beliefs towards utilization of reproductive health services are influencing this problem. ${ }^{8}$ Even though adolescent pregnancy is common in Nepal, there are not significant numbers of study conducted to find out the contributing factors of this problem in Terai region among majority of Muslim Community where early marriage and teenage pregnancy is common. This study had explored the causes of teenage pregnancy in Terai region among majority of Muslim adolescents and will be very effective for evidence-based planning to prevent early pregnancy.

\section{Methodology}

A cross-sectional study was conducted among pregnant teenagers visiting selected health facilities of Sunsari District in Eastern Nepal. There were 3 cluster of health facilities from which 1 Hospital out of 1 , one Primary Health Care Center out of 5 and two Health Posts out of 47 were selected randomly. Permission was taken from Municipalities, wards, health office and all included health institutions before study. All the pregnant women below the age of 20 who visited Antenatal Checkup (ANC) and attended out-patient department of these selected health facilities from May to July of 2019 were included in the study while women who were above 20 years and had history of teenage pregnancy were excluded from the study to prevent the recall bias as well as to get the most recent information about the causes of teenage pregnancy. Interview of 102 pregnant adolescents was conducted using semi structured questionnaire to get information about sociodemographic information, knowledge about causes and consequences of teenage pregnancy. Pre-testing of the questionnaire was done at Novel Hospital, Biratnagar and necessary modification of the questionnaire was done accordingly. Data was entered, coded, analyzed and interpreted according to the objective of the study using SPSS-21 software. The results obtained were expressed in mean, frequency and proportions. Chi square $(\chi 2)$ test was applied to determine significance of association if $P<0.05$ at $95 \%$ level of confidence.

The proposal was approved by Institutional Review Committee (IRC) of Manmohan Memorial Institute of Health Sciences (MMIHS) and development of questionnaire was done in close guidance of the research supervisor and adequate literature review. Informed consent was taken with each and every respondent, Health office and selected Health facilities of Sunsari District. During the study period, all the ethical considerations, as well as privacy and confidentiality was maintained to respect the human dignity and the principle of justice. The knowledge level was categorized as inadequate and adequate by the mean score of the knowledge obtained. The mean score obtained for knowledge on teenage pregnancy was $3.05 \pm 2.21$, the minimum and maximum knowledge score was 0 and 9 , respectively.

\section{Result}

The mean age of the respondents was $18.02 \pm 1.05$ years. Out of the total 102 respondents, $56.9 \%$ were of Muslim and the rest were Hindu by religion. More than $1 / 3$ of the respondents were illiterate, $1 / 5$ had primary education while only $1 \%$ had intermediate level of education. Regarding occupation, $86.3 \%$ were home maker and $11.8 \%$ were Labor, $13.7 \%$ respondents' earning was below poverty line; according to World Bank, those individuals whose daily income was less than $\$ 1.90$ were taken as below poverty line (Table 1). Study shows that the mean age of respondents at marriage was $16.69 \pm 1.09$ years, $31.4 \%$ of them were primigravida and $42.2 \%$ were pregnant at an age of 18 years for the first time. Among the respondents, $26.5 \%$ had experienced pregnancy loss of which $81.48 \%$ was still birth (Table 2). About the knowledge of teenage pregnancy, $21.6 \%$ had idea that pregnancy by 19 years is teenage pregnancy while more than half $(55.9 \%)$ had no idea about this. Among the respondents who had given correct response about teenage pregnancy, the sources of information were radio/TV, social media, books/newspaper, friends and so on.

About the causes of teenage pregnancy, majority of them had no idea followed by family pressure, and early marriage. Similarly, knowledge about the consequences of teenage pregnancy, majority $(41.3 \%)$ had reported stress and depression in mother, $18.6 \%$ said nothing will happen 
and $16.3 \%$ reported school drop-out while $15.7 \%$ had no knowledge about consequences of teenage pregnancy among both mother and child (Table 3). Only $28.4 \%$ had heard about family planning methods, among them $39.4 \%$ had heard about Depo-Provera which was $29.6 \%$ and $19.7 \%$ about pills and condom, respectively. Almost $1 / 3$ of the respondents had positive history of teenage pregnancy in family: either side (Table 4). Parent's pressure was the major cause of early marriage. Almost half of the respondents were pregnant because of the desire of their own parents whilst $29.4 \%$ listen to the desire of their in-laws. Other reasons were desire of couple and rape. Most of the (96.1\%) respondents were not using any methods of family planning; Depo-Provera and Implant were the common methods among the users. Among the contraceptives users, 13.7\% faced problem to get the contraceptives and the barriers were mainly Husband's avoidance followed by fear (Table 5).

Table I.Demographic characteristics of the respondents

\begin{tabular}{|c|c|c|}
\hline Factors & Frequency $(n=102)$ & Percentage (\%) \\
\hline \multicolumn{3}{|c|}{ Age (Years) (Mean age $=18.02 \pm 1.05)$} \\
\hline$\leq 15$ & 4 & 3.9 \\
\hline 16 & 4 & 3.9 \\
\hline 17 & 15 & 14.7 \\
\hline 18 & 42 & 41.2 \\
\hline$<20$ & 37 & 36.3 \\
\hline \multicolumn{3}{|c|}{ Ethnicity } \\
\hline Brahmin & 1 & 1 \\
\hline Janjati & 8 & 7.8 \\
\hline Dalit & 6 & 5.9 \\
\hline Madhesi & 29 & 28.4 \\
\hline Muslim & 58 & 56.9 \\
\hline \multicolumn{3}{|c|}{ Religion } \\
\hline Hindu & 44 & 43.1 \\
\hline Muslim & 58 & 56.9 \\
\hline \multicolumn{3}{|c|}{ Education Level } \\
\hline Illiterate & 38 & 37.3 \\
\hline Literate & 25 & 24.5 \\
\hline Primary & 21 & 20.6 \\
\hline $\begin{array}{c}\text { Secondary and } \\
\text { above }\end{array}$ & 18 & 17.7 \\
\hline \multicolumn{3}{|c|}{ Types of Family } \\
\hline Nuclear & 68 & 66.7 \\
\hline Joint & 34 & 33.3 \\
\hline Economic Status & & \\
\hline
\end{tabular}

\begin{tabular}{|c|c|c|}
\hline $\begin{array}{c}\text { Below Poverty } \\
\text { Line }\end{array}$ & 14 & 13.7 \\
\hline $\begin{array}{c}\text { Above Poverty } \\
\text { Line }\end{array}$ & 88 & 86.3 \\
\hline Occupation & 1 & 1 \\
\hline Agriculture & 12 & 11.8 \\
\hline Labour & 88 & 86.3 \\
\hline Home maker & 1 & 1 \\
\hline Student & & \\
\hline
\end{tabular}

Table 2.Distribution of Teenage Pregnancy

\begin{tabular}{|c|c|c|}
\hline Factors & $\begin{array}{c}\text { Frequency } \\
(\mathrm{n}=102)\end{array}$ & $\begin{array}{c}\text { Percentage } \\
(\%)\end{array}$ \\
\hline
\end{tabular}

Age at Marriage (Years) (mean=16.69 \pm 1.09 )

\begin{tabular}{|c|c|c|}
\hline 14 & 5 & 4.9 \\
\hline 15 & 8 & 7.8 \\
\hline 16 & 26 & 25.5 \\
\hline 17 & 39 & 38.2 \\
\hline 18 & 23 & 22.5 \\
\hline 19 & 1 & 1 \\
\hline \multicolumn{3}{|c|}{ Number of Pregnancy } \\
\hline $1 \mathrm{st}$ & 68 & 66.7 \\
\hline 2nd & 32 & 31.4 \\
\hline $3 r d$ & 2 & 2.0 \\
\hline \multicolumn{3}{|c|}{ Age during $1^{\text {st }}$ pregnancy } \\
\hline 14 & 1 & 1 \\
\hline 15 & 4 & 3.9 \\
\hline 16 & 9 & 8.8 \\
\hline 17 & 24 & 23.5 \\
\hline 18 & 43 & 42.2 \\
\hline 19 & 21 & 20.6 \\
\hline \multicolumn{3}{|c|}{ Pregnancy loss ( $n=102)$} \\
\hline Yes & 27 & 26.5 \\
\hline No & 75 & 73.5 \\
\hline \multicolumn{3}{|c|}{ Types of pregnancy loss(n=27) } \\
\hline Death of child after birth & 2 & 7.41 \\
\hline Still birth & 22 & 81.48 \\
\hline $\begin{array}{l}\text { Abnormalities in child } \\
\text { during birth }\end{array}$ & 3 & 11.11 \\
\hline
\end{tabular}

Table 6, shows the association between knowledge on teenage pregnancy and variables associated with it. The knowledge level was categorized as inadequate and adequate by the mean score of the knowledge obtained. The mean score obtained for knowledge on teenage pregnancy 
was $3.05 \pm 2.21$, the minimum and maximum knowledge score was 0 and 9 , respectively. Majority of the respondents, $69.6 \%$ had inadequate knowledge on teenage pregnancy and $30.4 \%$ had adequate knowledge on teenage pregnancy. Different variables such as age, types of family, economic status and occupation were not significantly associated with knowledge on teenage pregnancy while ethnicity, religion and education level were significantly associated. The knowledge level was categorized as inadequate and adequate by the mean score of the knowledge obtained. The mean score obtained for knowledge on Teenage pregnancy was $3.05 \pm 2.21$, the minimum and maximum knowledge score was 0 and 9 , respectively. Majority of the respondents, $69.6 \%$ had inadequate knowledge on teenage pregnancy. Early marriage was culturally accepted among the family of $1 / 3$ respondents. Almost $40 \%$ respondents were completely depend on their family about the decision of their pregnancy and could not put their opinion.

Table 3.Knowledge about Causes and Consequences of teenage pregnancy

\begin{tabular}{|c|c|c|}
\hline Factors & $\begin{array}{l}\text { Frequency } \\
\qquad(n=102)\end{array}$ & $\begin{array}{c}\text { Percentage } \\
(\%)\end{array}$ \\
\hline \multicolumn{3}{|c|}{ Causes of teenage pregnancy } \\
\hline Early marriage & 12 & 11 \\
\hline $\begin{array}{l}\text { Lack of Knowledge about } \\
\text { Family Planning }\end{array}$ & 4 & 3.7 \\
\hline Family Pressure & 31 & 28.4 \\
\hline $\begin{array}{l}\text { Unavailability of Family } \\
\text { planning Service }\end{array}$ & 1 & 0.9 \\
\hline Sexual Violence & 1 & 0.9 \\
\hline Don't Know & 56 & 54.9 \\
\hline Others & 4 & 3.9 \\
\hline \multicolumn{3}{|c|}{ Knowledge about consequences } \\
\hline Anemia in mothers & 1 & 0.8 \\
\hline $\begin{array}{l}\text { Congenital abnormalities in } \\
\text { baby }\end{array}$ & 5 & 4 \\
\hline Low birth weight in baby & 2 & 1.6 \\
\hline $\begin{array}{l}\text { Uterine prolapse in } \\
\text { mother }\end{array}$ & 2 & 1.6 \\
\hline Drop out from school & 21 & 16.7 \\
\hline $\begin{array}{l}\text { Stress and depression in } \\
\text { mother }\end{array}$ & 52 & 41.3 \\
\hline Premature Labor & 3 & 2.4 \\
\hline $\begin{array}{l}\text { Nothing will } \\
\text { happen }\end{array}$ & 19 & 18.6 \\
\hline Don't Know & 16 & 15.7 \\
\hline Others & 5 & 4.9 \\
\hline
\end{tabular}

Table 4. Heard about family planning and history of teenage pregnancy in family

\begin{tabular}{|c|c|c|}
\hline $\begin{array}{c}\text { Heard about family } \\
\text { planning methods } \mathbf{( n = 2 9 )}\end{array}$ & $\begin{array}{c}\text { Frequency } \\
(\mathbf{n = 1 0 2})\end{array}$ & $\begin{array}{c}\text { Percentage } \\
\text { (\%) }\end{array}$ \\
\hline Pills & 21 & 29.6 \\
\hline Depo-Provera & 28 & 39.4 \\
\hline IUCD & 2 & 2.8 \\
\hline Condom & 14 & 19.7 \\
\hline Norplant & 6 & 8.5 \\
\hline
\end{tabular}

History of teenage pregnancy in family-either side

\begin{tabular}{|c|c|c|}
\hline Yes & 32 & 31.4 \\
\hline No & 70 & 68.6 \\
\hline
\end{tabular}

Relation with the pregnant person of family $(n=32)^{* *}$

\begin{tabular}{|c|c|c|}
\hline Elder sister & 13 & 38.2 \\
\hline $\begin{array}{c}\text { Sister in law (maternal } \\
\text { house) }\end{array}$ & 1 & 2.9 \\
\hline Sister in law (own house) & 17 & 50 \\
\hline Cousin sister & 3 & 8.8 \\
\hline
\end{tabular}

Table 5.Reason of Early marriage and Teenage pregnancy

\begin{tabular}{|c|c|c|}
\hline Reason of early marriage & $\begin{array}{l}\text { Frequency } \\
(n=102)\end{array}$ & $\begin{array}{c}\text { Percentage } \\
(\%)\end{array}$ \\
\hline $\begin{array}{l}\text { Low socioeconomic status of } \\
\text { parents }\end{array}$ & 22 & 15.7 \\
\hline Poor academic condition & 2 & 1.4 \\
\hline Forced by parents & 92 & 65.7 \\
\hline Own desire & 23 & 16.4 \\
\hline Sexual violence & 1 & 0.7 \\
\hline \multicolumn{3}{|c|}{ Reason of teenage pregnancy } \\
\hline $\begin{array}{l}\text { Desire for the baby by in } \\
\text { laws }\end{array}$ & 30 & 29.4 \\
\hline $\begin{array}{l}\text { Desire for baby by own } \\
\text { parents }\end{array}$ & 49 & 48 \\
\hline Own desire & 6 & 5.9 \\
\hline Others & 17 & 16.7 \\
\hline \multicolumn{3}{|c|}{ Use of Family Planning Methods } \\
\hline Yes & 4 & 3.9 \\
\hline No & 98 & 96.1 \\
\hline \multicolumn{3}{|c|}{ Methods of Family Planning used $(n=4)$} \\
\hline Depo-Provera & 3 & 60 \\
\hline Implant & 2 & 40 \\
\hline \multicolumn{3}{|c|}{ Problem Faced in Getting Contraceptive $(n=102)$} \\
\hline Yes & 14 & 13.7 \\
\hline
\end{tabular}




\begin{tabular}{|c|c|c|}
\hline No & 88 & 86.3 \\
\hline \multicolumn{2}{|c|}{ Types of problems ( $\mathbf{n = 1 4 )}$} \\
\hline $\begin{array}{c}\text { Avoidance by } \\
\text { husband }\end{array}$ & 9 & 64.3 \\
\hline $\begin{array}{c}\text { Lack of knowledge } \\
\text { about } \\
\text { contraception }\end{array}$ & 2 & 14.3 \\
\hline Fear & 3 & 21.4 \\
\hline
\end{tabular}

Table 6.Association between demographic variables with knowledge level on teenage pregnancy

\begin{tabular}{|c|c|c|c|}
\hline \multirow[t]{2}{*}{ Factors } & \multicolumn{2}{|c|}{$\begin{array}{l}\text { Knowledge on Teenage } \\
\text { pregnancy }\end{array}$} & \multirow[t]{2}{*}{$p$-value } \\
\hline & Adequate & Inadequate & \\
\hline \multicolumn{4}{|c|}{ Ethnicity } \\
\hline Brahmin & 0 & 1 & \\
\hline Janajati & 5 & 3 & \\
\hline Dalit & 4 & 2 & 0.001 \\
\hline Madhesi & 16 & 13 & \\
\hline Muslim & 6 & 52 & \\
\hline \multicolumn{4}{|l|}{ Religion } \\
\hline Hindi & 25 & 19 & 0.001 \\
\hline Muslim & 6 & 52 & \\
\hline \multicolumn{4}{|c|}{ Education level } \\
\hline Illiterate & 6 & 32 & \\
\hline Literate & 4 & 21 & \\
\hline Primary & 8 & 13 & 0.001 \\
\hline Secondary & 13 & 4 & \\
\hline Intermediate & 0 & 1 & \\
\hline \multicolumn{4}{|c|}{ Types of family } \\
\hline Nuclear & 21 & 47 & 0.879 \\
\hline Joint & 10 & 24 & \\
\hline \multicolumn{4}{|c|}{ Economic Status } \\
\hline $\begin{array}{l}\text { Below poverty } \\
\text { line }\end{array}$ & 4 & 10 & 0.873 \\
\hline $\begin{array}{l}\text { Above Poverty } \\
\text { Line }\end{array}$ & 27 & 61 & \\
\hline \multicolumn{4}{|c|}{ Occupation } \\
\hline Agriculture & 1 & 0 & \\
\hline Labour & 5 & 7 & 0.127 \\
\hline $\begin{array}{l}\text { Home } \\
\text { maker }\end{array}$ & 24 & 64 & \\
\hline Student & 1 & 0 & \\
\hline
\end{tabular}

\section{Discussion}

Early marriage and teenage pregnancy in Terai especially among Muslim communities minority in Nepal is believed to be high because of their cultural and religious acceptance. This study explored that limited opportunity for education, lack of awareness program about teenage pregnancy, lack of knowledge about consequences of teenage pregnancy, cultural acceptance for early marriage, parent's behavior and lack of knowledge and access on family planning methods as major contributing factors for teenage pregnancy. Nepal is one of the top 10 countries which have highest rate of child marriage and teenage pregnancy in the world and third highest rate of child marriage and teenage pregnancy in South Asia after Bangladesh and India. ${ }^{2}$ This study showed that teenage pregnancy increases with age, from $3 \%$ among women age 15 to $37 \%$ among women age 19 which is similar to the findings of NDHS 2016 which revealed that teenage pregnancy increases with age, $2 \%$ among women age 15 to $36 \%$ among women age 19.6 In this study, 38\% of the respondents said that lower level of education was contributing factor of teenage pregnancy, which was similar to the finding of the study by Chalise and Bajrachraya which found that some of the respondents were already dropouts from school, while others were deprived of the chance with secondary education. ${ }^{9}$ The low literacy levels may have an impact on teenage pregnancy. About $87 \%$ of the respondents in this study, whose main occupation was home maker; felt their occupation was main contributing factor of teenage pregnancy. This result was similar to the study conducted by Chalise and Bajrachraya which showed that the risk was fifteen times higher in respondents with no employment. ${ }^{9}$ This could be the consequence of early marriage and early pregnancy as well as the cause of this problem because these girls had no access of higher education which might create better employment opportunities.

In this study, $67 \%$ of the respondents said cultural acceptance for early marriage was contributing factor of teenage pregnancy. This finding was similar to the finding of Acharya et al. which revealed that early age at marriage is culturally acceptable in south Asian culture, which seems to add risk of teenage pregnancy. ${ }^{3}$ Another study also showed $94 \%$ had cultural acceptance for early marriage. ${ }^{9}$ In this study, 32\% were pregnant with their first child and $27 \%$ of teenagers had experienced pregnancy loss out of which $22 \%$ had still birth. This result was similar to the NDHS 2016 which revealed that number of pregnancy with first child increases and there is increase in pregnancy loss due to lack of birth spacing. ${ }^{6}$ The study showed that $60 \%$ of the respondents said that being religious factor like being Muslim was contributing factor of teenage pregnancy. 
This finding is similar to the study done by NDHS which revealed that teenage pregnancy is double among Muslim community residing in Terai compared to other religion. ${ }^{6}$ which showed early pregnancy is common among Muslim because of religious faith and resistance to change. Another factor of teenage pregnancy, was lack of knowledge about it (78\%) and study conducted by Chalise and Bajrachraya also revealed that the risk was fifteen times higher in respondents with no education about Teenage pregnancy. ${ }^{9}$

A study conducted by Atreya A. showed that Nepal lack of knowledge on Consequences of teenage pregnancy is also contributing to teenage pregnancy. ${ }^{10}$ Lack of knowledge about the consequences of teenage pregnancy was contributing factor of teenage pregnancy according to $38 \%$ of the respondents of this study. In present study, $28.4 \%$ had heard about family planning methods while only $3.9 \%$ had use family planning methods which have similar findings with the study conducted by Suresh Mehata reported that Muslims and Terai Madhesi were less likely to use family planning compared to other caste/ ethnic groups. ${ }^{11}$ The fears, beliefs and perceptions, culture associated with contraceptive use could be the attributed factors. This study showed that $66 \%$ of the respondents felt that Forced by parents were main factors of Early marriage and teenage pregnancy. In a study conducted in Dhaulagiri explored that Family pressure was also contributing factor of teenage pregnancy. ${ }^{9}$ Next study conducted in Palpa showed that about $56 \%$ respondents still believed that the right to make decisions about a child's marriage lies with the father and mother. ${ }^{12}$ Parental pressure in marriage and pregnancy in common in Nepalese culture. In this study, age, types of family, economic status and occupation were not significantly associated with knowledge on teenage pregnancy while ethnicity, religion and education level showed significant association. The study was carried out in limited area so it may not represent the whole pregnant teenagers.

\section{Conclusion}

Early marriage and teenage pregnancy was common in the study area where majority of the respondents were from Muslim community. Parent's pressure was the major cause of early marriage and early pregnancy. Knowledge about the risk and drawbacks of early marriage and early pregnancy should be increased not only among teenage girls but also to their parents, in-law's and husbands to change the attitude and practice towards teenage pregnancy. Concerned authorities should have special program focus on high risk groups and lunch awareness rising program. Proper implementation of the legal provision of marriage after the age of 20 is also an urgent need to prevent teenage pregnancy.

\section{Sources of Funding: None}

\section{Conflict of Interest: None \\ References}

1. Sayem AM, Nury ATM. Factors associated with teenage marital pregnancy among Bangladeshi women. Journal of Reproductive Health 2011; 8(1): 16-22. DOI: https:// doi.org/10.1186/1742-4755-8-16

2. Ending Child Marriage: Progress and prospects [Internet]. Unicef.org. 2013 [cited 17 August 2020]. Available from: https://www.unicef.org/media/files/ Child_Marriage_Report_7_17_LR..pdf.

3. Acharya DR, Bhattarai R, Poobalan A et al. Factors associated with teenage pregnancy in South Asia. Health Science Journal 2014; 5(1): 3-14. DOI: https:// www.hsj.gr/medicine/factors-associated-withteenage-pregnancy-in-south-asia-a-systematic-review. php?aid=3616.

4. Poudel S, Upadhaya N, Khatri RB, Ghimire PR. Trends and factors associated with pregnancies among adolescent women in Nepal: Pooled analysis of Nepal Demographic and Health Surveys. (2006, 2011 and 2016). PLOS ONE 13(8): e0202107. https://doi.org/10.1371/journal. pone.0202107.

5. Dias T, Wijesinghe E, Abeykoon S, Ganeshamoorthy $\mathrm{P}$, Kumarasiri S, Kodithuwakku M et al. Pregnancy outcome in extremes of reproductive age at a tertiary care hospital. Srilanka Journal of Obstretics and gynaecology 2013; 35(3): 77-79. DOI: http://dx.doi. org/10.4038/sljog.v35i3.6334.

6. Nepal Demographic and Health Survey [Internet]. Dhsprogram.com. 2016 [cited 19 August 2020]. Available from: https://www.dhsprogram.com/pubs/ pdf/fr336/fr336.pdf.

7. Kirby D, Coyle KJC, review ys. School-based programs to reduce sexual risk-taking behavior. Children and Youth Services Review 1997; 19(5-6): 415-436. https://ideas. repec.org/a/eee/cysrev/v19y1997i5-6p415-436.html.

8. Mauna JB. Factors Contributing to High Prevalence of Teenage Pregnancy in Lindi Municipality, Tanzania. The Open University Of Tanzania 2015; 12(2): 105-109. http://repository.out.ac.tz/id/eprint/1264.

9. Chalise S, Bajracharya S. Contributing factors of Teenage Pregnancy among Pregnant Teenagers at selected hospitals of Dhaulagiri Zone. Journal of Chitwan Medical College 2016; 6(17): 8-13. Available from: http://www. jcmc.cmc.edu.np.

10. Nepal S, Atreya A, Kanchhan T. Teenage Pregnancies in Nepal - The Problem Status and Socio-Legal Concerns. JNMA; journal of the Nepal Medical Association 2018; 56(211): 678-682. DOI: https://doi.org/10.31729/ jnma.3571.

11. Mehata S, Paudel Y, Dotel B, Singh D, Poudel P, Barnett 
S. Inequalities in the Use of Family Planning in Rural Nepal. BioMed Research International 2014; 2014: 1-7. http://dx.doi.org/10.1155/2014/636439.

12. Thapa B, Macer D. Bases of Early Marriage \& Consequences on the Well-being of Mother and Child in Jhirubas, Palpa, Nepal. Eubios Journal of Asian and International Bioethics 2018; 28(March): 72-86. Available at: https://www.academia.edu/42181755/ Bases_of_Early_Marriage_and_Consequences_on_ the_Well_being_of_Mother_and_Child_in_Jhirubas_ Palpa_Nepal [Accessed 19 August 2020]. 